\title{
The Superconductivity of Gold Alloys
}

\author{
H. R. Khan and Ch. J. Raub \\ Forschungsinstitut für Edelmetalle und Metallchemie, Schwäbisch Gmünd, West Germany
}

\begin{abstract}
While no intermetallic compound of gold has yet been found to exhibit superconductivity at temperatures that would make it industrially useful, the investigation of these compounds has been of value in increasing our understanding of the phenomenon. This paper presents a general survey of the extensive studies that have so far been made.
\end{abstract}

The success of Kammerlingh-Onnes in liquefying helium in 1908 led to a workable fluid with a normal boiling point of $4.2 \mathrm{~K}$. In this liquid he measured the temperature dependence of electrical resistivity of gold, mercury and platinum. Both gold and platinum exhibited a temperature independent resistivity at $4.2 \mathrm{~K}$, but in the case of mercury the electrical resistivity vanished completely below this temperature. Kammerlingh-Onnes called the state of matter with no electrical resistance "superconducting state" and the temperature at which matter enters into this state "critical temperature".

After 66 years of active research in this field, several hundred superconducting binary and ternary alloys have been discovered with critical temperatures as high as $23.4 \mathrm{~K}$. Silver, copper and gold, the best electrical conductors at room temperature, do not show any sign of superconductivity above a few millidegrees. In general elements which enter into the superconducting state easily are poorer metallic conductors, such as niobium, tantalum and lead.

To understand this peculiar mechanism of superconductivity, experimentalists measured the critical temperatures of elements and alloys and related them to other solid state properties. They found that the electronic structure of the material which gives a high electron density of states at the Fermi level is a parameter of primary importance for the critical temperature. The most favourable structure to superconductivity seems to be the $A-15$ or $\beta-W$ structure. B. T. Matthias (1) discovered an empirical rule which predicts that alloys with average numbers of valence electrons per atom on the lower side of valences 5 and 7 will have high critical temperatures. At the same time theoreticians tried to understand superconductivity, and Fröhlich (2) first related critical temperatures of different isotopes of an element by the expression

$$
T_{c} \propto M^{-1 / 2},
$$

where $M$ is the atomic weight. The experimental confirmation of this formula led to the discovery that superconductivity is due to some kind of electronlattice interaction. Finally, Bardeen, Cooper and Schrieffer (3) gave a model to explain the phenomena of superconductivity. Their model shows that in the superconducting state the condensation of pairs of conduction electrons into a lower energy state takes place. This condensation process involves the interaction between the conduction electrons and the crystal lattice-a process which is also responsible for the electrical resistance in the normal (nonsuperconducting) state. This model could explain why superconductivity occurs in poorer metallic conductors rather than in good electrical conductors. The critical temperature is related to the Debye temperature $\theta_{\mathrm{D}}$ and the electron density of states $\mathrm{N}(\mathrm{O})$ and the electron-phonon interaction parameter $\mathrm{V}$ by the formula

$$
T_{c} \propto \theta_{D} \exp .-\left(\frac{1}{N(O) V}\right)
$$

In spite of the success in explaining the superconducting behaviour, it is difficult to calculate the critical temperature of the material or even predict if a phase will superconduct or not, because the interaction energy parameter $N(\mathrm{O}) \mathrm{V}$, which is in the exponential term, is affected by several solid state parameters like lattice constant, electron density of states, and ionic mass, in a complicated way.

Gold itself does not become a superconductor above the millidegree range even if it is extremely pure, while none of the gold-rich solid solutions so far studied have proved to be superconducting. In forming solid solutions with them in general, gold lowers the $T_{c}$ of other elements, for example those of niobium and vanadium. Therefore the interest of researchers has been concentrated on the intermetallic compounds.

The very first intermetallic compound to be discovered was the C15-type phase $\mathrm{Au}_{2} \mathrm{Bi}$ (4) by de Haas in 1929. As a matter of fact its existence was concluded first from superconducting measurements. Since this time superconductivity and other solid 


\begin{tabular}{|c|c|c|c|c|c|c|c|c|c|c|c|c|c|c|c|c|c|c|}
\hline H & & & & & & & & & & & & & & & & & \multicolumn{2}{|c|}{$\mathrm{He}$} \\
\hline $\mathrm{Li}$ & $\mathrm{Be}$ & & & & & & & & & & & B & C & $N$ & $\mathbf{N}$ & $\mathrm{O}$ & $\mathrm{Ne}$ & \\
\hline $\mathrm{Na}$ & $\mathrm{Mg}$ & & & & & & & & & & & $\mathrm{Al}$ & $\mathrm{Si}$ & i & $\mathbf{P}$ & $\mathrm{S}$ & \begin{tabular}{l|l}
11 & $\mathrm{Ar}$
\end{tabular} & \\
\hline K & $\mathrm{Ca}$ & $\mathrm{Sc}$ & $\mathrm{Ti}$ & V & $\mathrm{Cr}$ & $\mathrm{Mn}$ & $\mathrm{Fe}$ & $\mathrm{Co}$ & \begin{tabular}{l|l}
0 & $\mathrm{Ni}$
\end{tabular} & $\mathrm{Cl}_{\mathrm{i}}$ & $\begin{array}{ll}\mathrm{u} & \mathrm{Zn}\end{array}$ & $\mathrm{Ga}$ & $\mathrm{Ge}$ & e & \begin{tabular}{l|l} 
As & $\mathrm{S}$
\end{tabular} & Se & \begin{tabular}{l|l}
$\mathbf{r}$ & $\mathrm{Kr}$
\end{tabular} & \\
\hline $\mathbf{R b}$ & $\mathrm{Sr}$ & $\mathbf{Y}$ & $\mathrm{Zr}$ & $\mathrm{Nb}$ & Mo & To & $R_{t}$ & u $\mathrm{Rh}$ & $P$ & $A_{\xi}$ & $\mathrm{g} \mid \mathrm{Cd}$ & In & Sn & n & \begin{tabular}{l|l}
$S b$ & $T$
\end{tabular} & $\mathrm{Te}$ & $\mathrm{Xe}$ & \\
\hline Cs & $\mathrm{Ba}$ & $\mathrm{La}$ & $\mathrm{Hf}$ & Ta & W & $\mathrm{Re}$ & 0 & Ir & . & $A_{l}$ & $\mathrm{u} \quad \mathrm{Hg}$ & $\mathrm{Tl}$ & & \begin{tabular}{l|l}
$\mathbf{b}$ & $\mathrm{B}$
\end{tabular} & Bi & \begin{tabular}{l|l} 
Po & $A$ \\
\end{tabular} & \begin{tabular}{l|l} 
It & $\mathrm{Rr}$ \\
\end{tabular} & \\
\hline $\mathrm{Fr}$ & Ra & Ac & & & & & & & & & & & & & & & & \\
\hline & & & & & & $\mathrm{Pr}$ & Nd & $\mathbf{P m}$ & Sm & $\mathrm{Eu}$ & $\mathrm{Gd}$ & $\mathrm{Tb}$ & Dy & Ho & $\mathbf{E r}$ & $\mathrm{Tm}$ & $\mathrm{Yb}$ & $\mathrm{Lu}$ \\
\hline & & & & & & $\mathrm{Pa}$ & $\mathbf{U}$ & $N_{p}$ & $\mathbf{P u}$ & Am & $\mathrm{Cm}$ & Bk & Cf & Es & $\mathrm{Fm}$ & Md & No & Lw \\
\hline
\end{tabular}

$\square \begin{aligned} & \begin{array}{l}\text { binary } \\ \text { superconductor }\end{array} \quad \begin{array}{l}\text { ternary } \\ \text { superconductor }\end{array} \quad \begin{array}{l}\text { investigated - not } \\ \text { superconductor }\end{array}\end{aligned}$

Fig. 1 The distribution of the superconducting compounds of gold in the Periodic Table

state properties of gold alloys have been studied extensively and new superconducting gold-phases have emerged. The present article gives a general survey of the superconductivity of gold alloys.

The periodic chart in Figure 1 shows the distribution of gold-containing binary and ternary superconducting compounds along with those which have been checked and are found not to be superconductors.

None of the compounds formed by elements of Group IA and IB showed superconductivity. Phases checked have been $\mathrm{Au}_{2} \mathrm{Na}(5)$ and $\mathrm{AuNa}_{2}(6), \mathrm{Au}_{5} \mathrm{~K}$ (5) and $\mathrm{Au}_{5} \mathrm{Rb}$ (5), as well as $\mathrm{AuCu}$ and $\mathrm{Cu}_{3} \mathrm{Au}$. In Group IIA and IIB beryllium, calcium, barium and zinc compounds are superconducting, their transition temperatures ranging between 0.34 and $2.64 \mathrm{~K}$, as shown in Table I. The compound $\mathrm{Au}_{5} \mathrm{Ba}$ (11)

\begin{tabular}{|l|l|c|c|}
\hline \multicolumn{3}{|c|}{ Table I } \\
Superconducting Compounds of Gold with the \\
Elements of Group II A and II B
\end{tabular}

proved to be of a special importance to superconductivity since it exists in a homogeneity range between $\mathrm{BaAu}_{3.5}$ and $\mathrm{BaAu}_{6 \cdot 5}$. The relationship between lattice parameters, superconducting transition temperature and composition of this phase can be seen in Figure 2. On the basis of these results the authors predicted a $T_{c}$ of gold in the millidegree range.

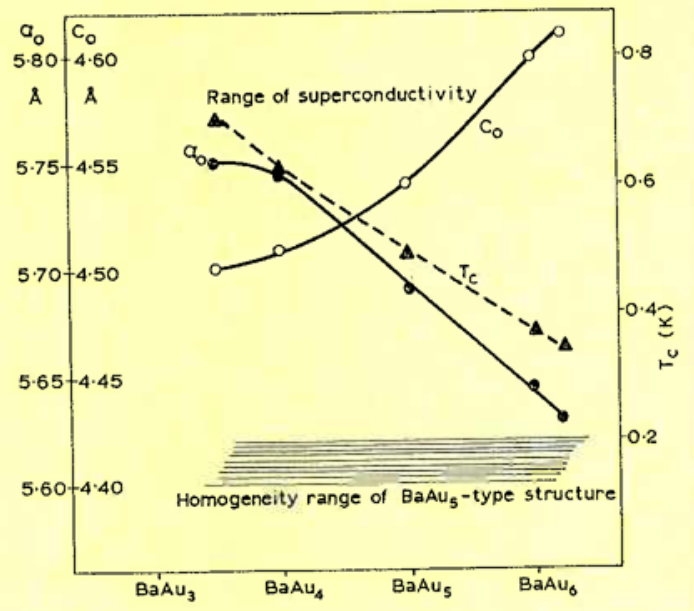

Fig. 2 Relationship between lattice parameters, composition and superconductivity in the $\mathrm{BaAu}_{5}-$ type structure at $700^{\circ} \mathrm{C}$ 
Table II

Superconducting Compounds of Gold with the Elements of Group III A and III B

\begin{tabular}{|c|c|c|c|}
\hline Compound & $\mathrm{T}_{\mathrm{c}}(\mathrm{K})$ & $\begin{array}{l}\text { Crystal } \\
\text { Structure }\end{array}$ & Ref. \\
\hline $\mathrm{AuGa}$ & 1.2 & B31 & (5) \\
\hline $\mathrm{AuGa}_{2}$ & 0.34 & $\mathrm{Cl}$ & (12) \\
\hline $\mathrm{AuIn}_{2}$ & $.096-.093$ & - & (12) \\
\hline AuIn & $0.4-0.6$ & complex & (5) \\
\hline $\mathrm{AlAu}_{4}$ & $0.4-0.7$ & as $\mathrm{A} 13$ & (5) \\
\hline $\mathrm{Au} \mathrm{u}^{\prime} \mathrm{T} !$ & 1.92 & 一 & (9) \\
\hline
\end{tabular}

Table II lists the superconducting compounds of gold with the elements of Group IIIA and IIIB, their crystal structures and transition temperatures. The highest critical temperature is that of $\mathrm{AuTl}\left(\mathrm{T}_{\mathrm{c}}==\right.$ 1.92). Partial substitution of gold by palladium in a binary compound $\mathrm{AuGa}_{2}$ (12) raises the $\mathrm{T}_{\mathrm{c}}$ from .34 to $1.79 \mathrm{~K}$. This shows the general trend that the addition of an unfilled d-band element often raises the $T_{c}$ in ternary compounds.

Of the Group IVB transition metals titanium, zirconium and hafnium, none forms superconducting phases with gold. This is even true for the A-15-type $\mathrm{Ti}_{3} \mathrm{Au}$. Due to stabilisation of the b.c.c. $\beta$-phase, gold enhances the $T_{c}$ of zirconium (13) to about 2.80 $\mathrm{K}$, but decreases the $\mathrm{T}_{\mathrm{c}}$ of $\mathrm{Ti}-\mathrm{Rh}$ (14) alloys.

Germanium (15), tin (16) and lead (17) form superconducting compounds with gold. With tin and lead phases it has to be remembered that free tin or lead might have caused the superconductivity.

The composition and structure of superconducting $\mathrm{Au}-\mathrm{Ge}\left(\mathrm{T}_{\mathrm{c}}=2.7 \mathrm{~K}\right)$ are not established for sure, since it is only formed by rapid quenching. Compounds $\mathrm{AuSn}$ and $\mathrm{AuSn}_{4}$ have hexagonal and primitive cubic structures respectively. Their $\mathrm{T}_{c}$ values are between 2.0 and $3.8 \mathrm{~K}$. Normally the addition of gold to lead lowers its $T_{c}$, yet there is a compound $\mathrm{Au}_{\mathrm{x}} \mathrm{Pb}_{\mathrm{y}}$ of unknown crystal structure with a $T_{c}$ of $7.2 \mathrm{~K}$. Since this value is identical with the one for pure lead $\left(T_{c}=\right.$ $7.193 \mathrm{~K}$ ) the cause for superconductivity might be the preserves of filaments of lead.

Of the Group VA elements only antimony (18) and bismuth react to form a superconductor. $\mathrm{Au}_{2} \mathrm{P}_{3}$ is not superconducting above $10 \mathrm{mK}, \mathrm{AuSb}_{2}$ is at $0.58 \mathrm{~K}$ and $\mathrm{Au}_{2} \mathrm{Bi}$ as mentioned at $1.84 \mathrm{~K}$.

Much work has been done on the low temperature properties of the intermetallic compounds of gold with the Group VB elements vanadium, niobium and tantalum, especially since all form A15 phases. $\mathrm{Nb}_{3} \mathrm{Au}$ (19) has the highest $\mathrm{T}_{\mathrm{c}}$ of 10.5 and $\mathrm{Ta}_{3} \mathrm{Au}$ (20) the lowest at $0.5 \mathrm{~K}$. $A \mathrm{u}_{4} \mathrm{~V}(21)$ is one of the few ferromagnets, where none of the constituent elements are ferromagnetic.
Substitution of rhodium (unfilled $4 \mathrm{~d}$ band) and platinum (unfilled $5 \mathrm{~d}$ band) for gold in $\mathrm{Nb}_{3} \mathrm{Au}$ raise the $T_{c}$ to 10.9 for $\mathrm{Nb}_{3} \mathrm{Au}_{0 \cdot 98} \mathrm{Rh}_{0.02}$ (22) and to $12.5 \mathrm{~K}$ for $\mathrm{Nb}_{3} \mathrm{Au}_{0.7} \mathrm{Pt}_{0.3}$ (19). A further increase in rhodium concentration lowers the $T_{c}$.

Metallurgical conditions have important influence on the superconducting behaviour of these ternary alloys. As a rule of thumb one can say that in general heterogeneous alloys exhibit higher $T_{c}$ 's than homogeneous phases of the same composition. The classic examples of inhomogeneous systems having high transition temperatures are $\mathrm{Nb}_{3}(\mathrm{Al}, \mathrm{Ge})(23)$ and $\mathrm{Nb}_{3} \mathrm{Ga}(24)$.

The $\mathrm{Nb}_{3} \mathrm{Au}$ (25) phase occurs up to $1560^{\circ} \mathrm{C}$. Its maximum homogeneity range is between 75 and 81 atomic per cent niobium. If $\mathrm{Nb}_{3} \mathrm{Au}$ is annealed at $1000,1200,1400$ and $1550^{\circ} \mathrm{C}$ and is afterwards quenched the homogeneity of the samples increases with the annealing temperature, yet $T_{c}$ decreases with improving homogeneity (Figures 3 and 4). A reason for this could be the atomic disordering due to annealing at higher temperatures.

Recently we investigated the superconducting behaviour of the alloy $\mathrm{Nb}_{4} \mathrm{Au}_{0 \cdot 25} \mathrm{Pt}_{0 \cdot 75}$ (26). In the as-cast state the $T_{c}$ is $10.0 \mathrm{~K}$ but annealing for 14 days at $1200^{\circ} \mathrm{C}$ decreased the transition temperature

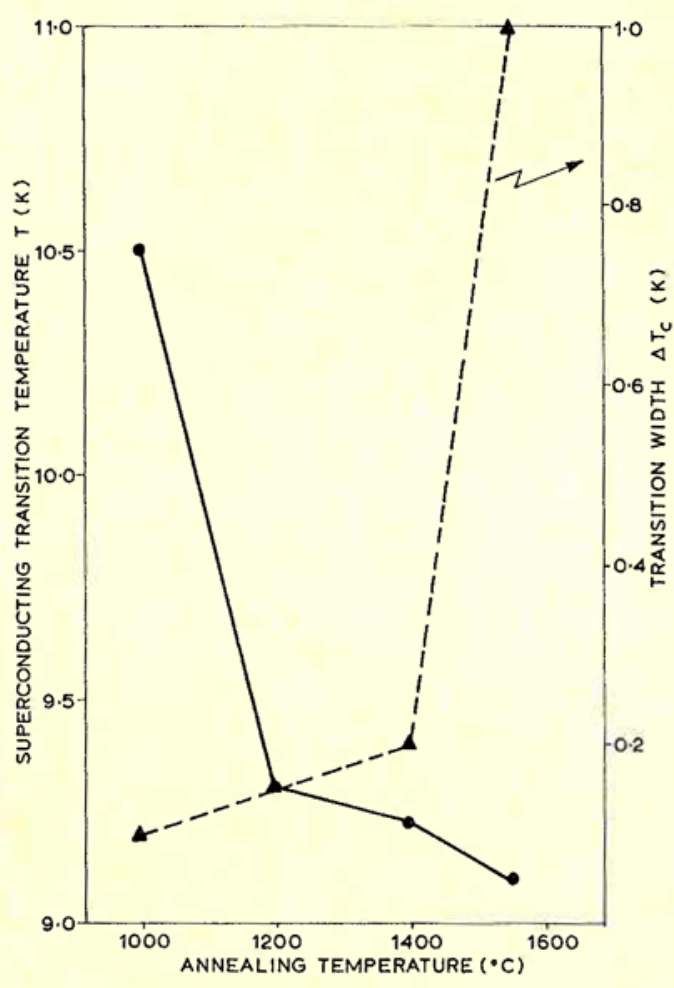

Fig. 3 Superconducting transition temperatures and transition widths of $\mathrm{Nb}_{3} \mathrm{Au}$ alloys annealed at different temperatures 


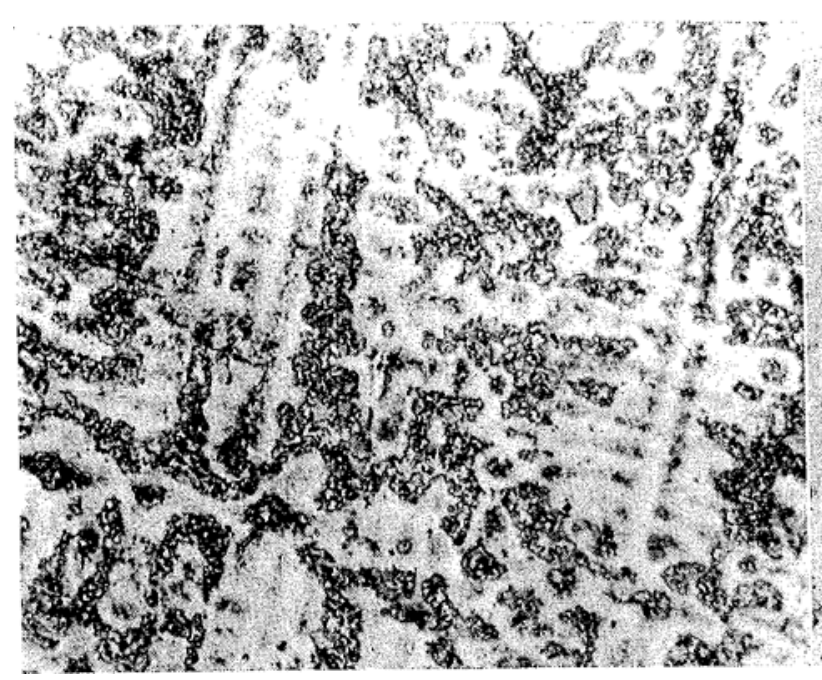

A Annealed at $1000^{\circ} \mathrm{C}, 4$ weeks, fast quenched in water

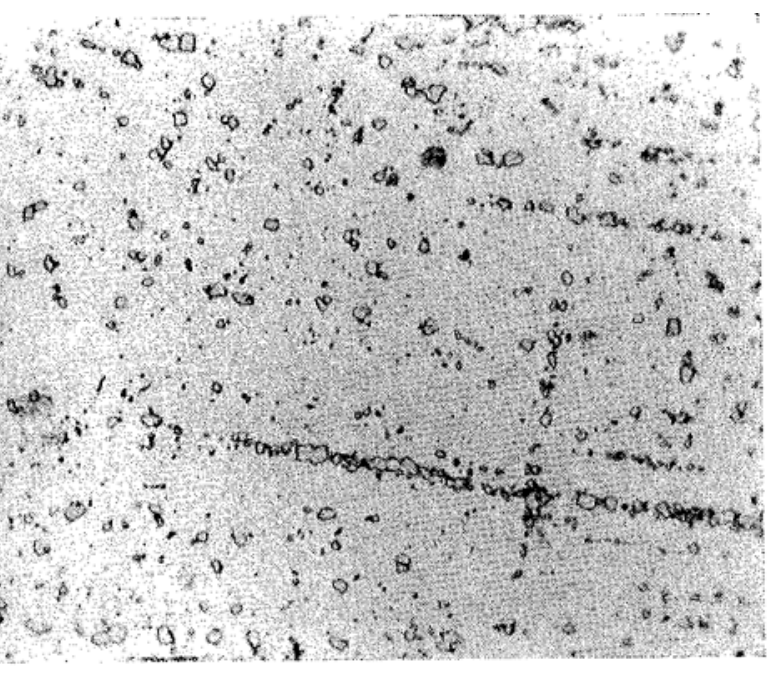

B Annealed at $1200^{\circ} \mathrm{C}$, I. week, fast quenched in oil

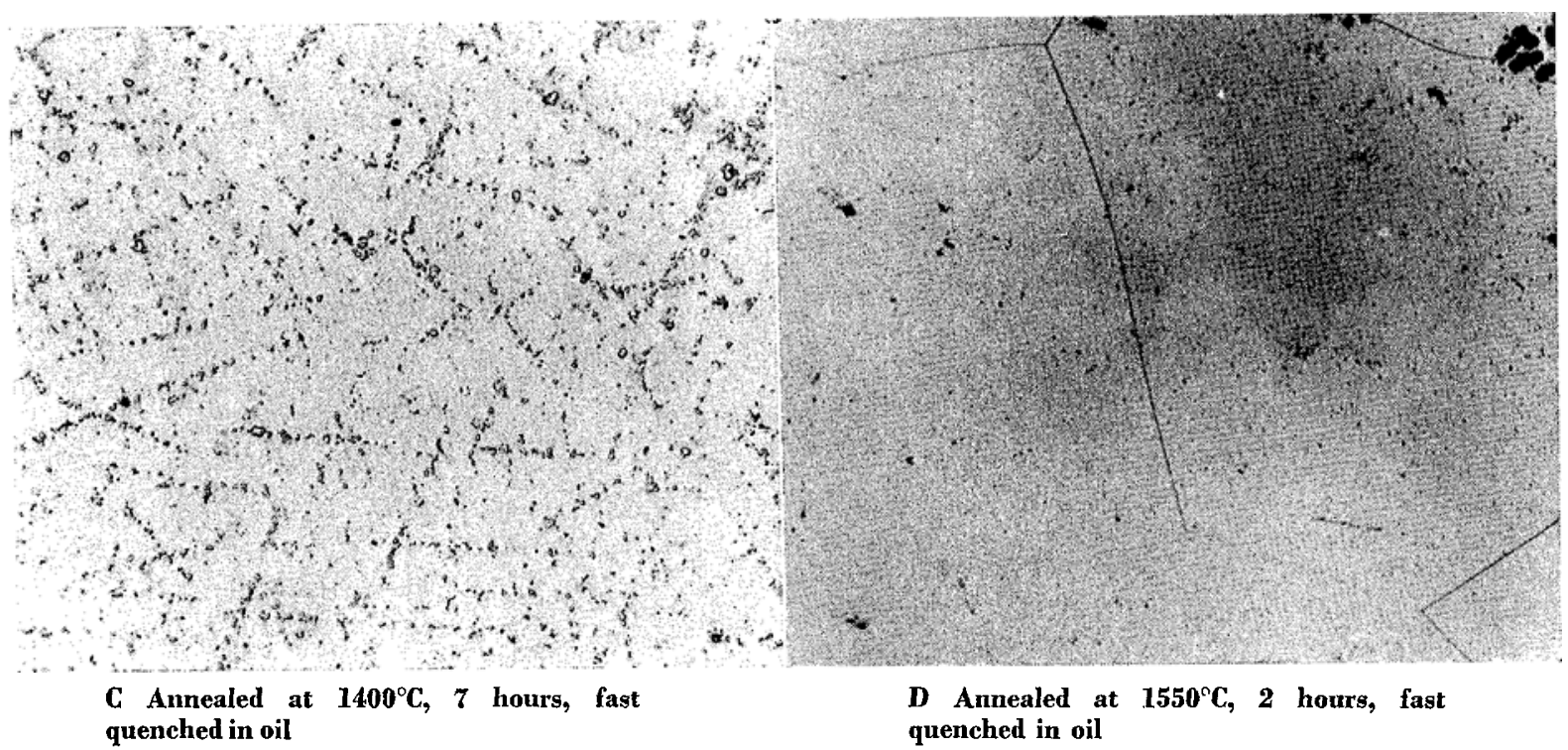

Fig. 4 Microstructures of $\mathrm{Nb}_{3}$ Au alloys. The homogeneity of the alloys increases with the annealing temperature but the critical temperature decreases with increasing homogeneity

All $\times \mathbf{5 0 0}$

down to $5.0 \mathrm{~K}$. In contrast, for $\left.\mathrm{Nb}_{3} \mathrm{Pt}_{\left(1_{-\mathrm{x}}\right)}\right) \mathrm{Au}_{\mathrm{x}}$ alloys, annealing increased the superconducting transition temperature as shown in Figure 5. The story of the relationship of multiple phases to the transition temperature is not clear yet; once completely understood it would be of great help in raising the $T_{c}$.

$\mathrm{V}_{3} \mathrm{Au}$ also crystallises in the $\mathrm{A}-15$ structure. It has the same valence electron concentration as $\mathrm{Nb}_{3} \mathrm{Au}$, but its critical temperature is only $0.74 \mathrm{~K}$. Van Reuth and others (27) were able to raise its $T_{c}$ to $2.98 \mathrm{~K}$ by low temperature annealing. They also measured the order parameter by X-ray diffraction technique and found that atomic ordering increased. This ordering raises the electron density of states and subsequently the critical temperature. From their measurements they introduced an ordering parameter in superconductivity. From a technological point of view this increase in $T_{c}$ by $2 \mathrm{~K}$ does not sound very interesting, but its physical implications are important. Once the ordering mechanism is fully understood and could be utilised, superconductors having a $T_{c}$ value of at least $30 \mathrm{~K}$ can be imagined. This would have an enormous impact on the technical applications.

Among the Group VI A elements only tellurium forms a superconducting phase $\mathrm{Au}_{3} \mathrm{Te}_{5}(28)\left(\mathrm{T}_{\mathrm{c}}=\right.$ 1.62). None of the gold compounds with elements of the V1 B to VIII B groups superconducts. Other phases worth mentioning are $\mathrm{AuTh}_{2}(6)\left(\mathrm{T}_{\mathrm{c}}=3.65\right)$ and AuLu (29) $\left(\mathrm{T}_{\mathrm{c}}=0.35\right)$. A pseudobinary carbide $\mathrm{AuC}_{1 \cdot 3} \mathrm{Y}_{0 \cdot 9}(30)$ was stated to have a $\mathrm{T}_{\mathrm{c}}$ of $10.1 \mathrm{~K}$, but again the possibility of filaments of the binary carbide being present cannot be excluded. 


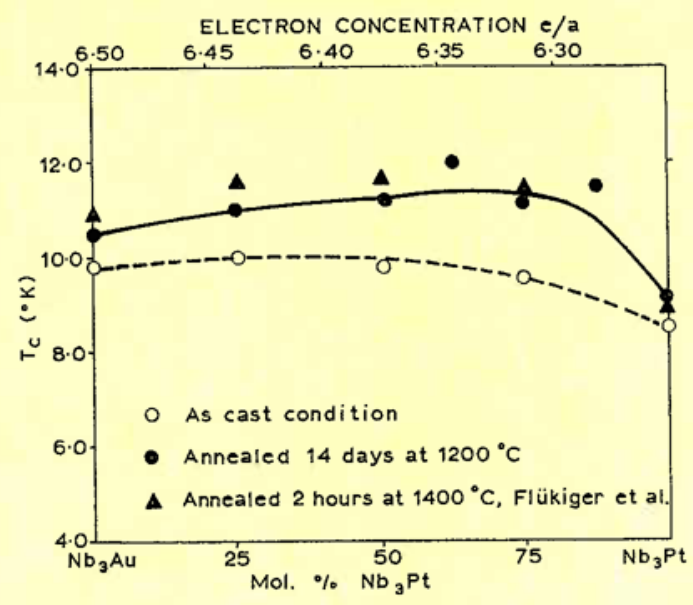

Fig. 5 Variation of superconducting transition temperature of $\mathrm{Nb}_{3} \mathrm{Pt}_{(1-x)} \mathrm{Au}_{\mathbf{x}}$ alloys in the as-cast and annealed conditions as a function of mol. $\% \mathrm{Nb}_{3} \mathrm{Pt}$

The technological applications of superconductivity are emerging, but for materials research and solid state physics it has already become of increasing importance. Scientists involved have two things in mind, to synthesise a superconducting material having mechanical properties suitable to industrial needs and at the same time to understand the phenomenon in order to help in synthesising superconductors of high critical temperatures.

The investigation of gold compounds has helped modern solid state physicists to understand more about superconductivity. Whether a gold compound will ever show a $T_{c}$ above $20 \mathrm{~K}$ one cannot predict. In no other field of science does the number of theoretical explanations of experimentally found effects surpass by so much the number of experimentally confirmed theoretical predictions as in the field of superconductivity.

\section{References}

1 B. T. Matthias, Phys. Rev., 1955, 97, 74

2 H. Fröhlich, Phys. Rev., 1950, 79, 845

3 J. Bardeen, L. N. Cooper and J. R. Schrieffer, Phys. Rev., $1957,108,1175$

$4 \mathrm{~W}$. J. de Haas and J. Turriaanse, Proc. Acad. Sci Amsterdam, 1932, 35, 748

5 D. C. Hamilton, Ch. J. Raub, B. T. Matthias, E. Corenzwit and G. W. Hull, Jr., F. Phys, Chem. Solids, $1965,26,665$

6 E. E. Havinga, H. Damsma and P. Hokkeling, $\mathcal{F}$. Less-Common Metals, 1972, 27, 281

7 C. E. Olsen, B. T. Matthias and H. H. Hill, Z. Phys., 1967, 200,7

8 Ch. J. Raub and D. C. Hamilton, F. Less-Common Metals, 1964, 6, 486

9 B. W. Roberts, Progress in Cryogenics, Vol. 4, Heywood, London, 1964, p. 160

10 D. Farrell, J. G. Park and B. R. Coles., Phys. Rev. Letters, 1964, 13, 328
11 G. Arrhenius, Ch. J. Raub, D. C. Hamilton and B. T. Matthias, Phys. Rev. Letters, 1963, 11, 313

12 J. H. Wernick, A. Meuth, T. H. Geballe, G. Hull and J. P. Maita, F. Phys. Chem. Solids, 1969, 30, 1949

13 B. W. Roberts, Progress in Cryogenics, Vol. 4, Heywood, London, 1964, p. 160

14 Ch. J. Raub., Z. Phys. 1964, 178, 216

15 B. Stritsker, and H. Wuhl, Z. Phys, 1971, 243, 361; H. L. Luo, M. F. Merriam and D. C. Hamilton, Science, 1964, 145, 581

16 E. Klokholm, and C. Chion, Acta Met., 1966, 14, 565; H. I. Luo, M. F. Merriam, and D. C. Hamilton, Science $1964,145,581$

17 Ref. 6 and V. Sadogopan, E. Pollard and H. C. Gatos, Solid State Commun., 1965, 3, 97; H. L. Caswell, Phys. Letters, 1964, 10, 44

18 B. T. Matthias, T. H. Geballe, and V. B. Compton, Rev. Mod. Phys., 1963, 35, 1

19 P. Spitzli, R. Flükiger, F. Heininger and J. Muller, Phys. Letters, 1969, 30 A, 170

20 H. L. Luo, E. Vielhaber and E. Corenzwit, Z. Phys., $1970,230,443$

21 L. Creveling, H. L. Luo and G. S. Knapp, Phys. Rev. Letters, 1967, 18, 851

22 S. T. Zegler, Phys. Rev., 1965, 137 A, 1438

23 G. Arrhenius, E. Corenzwit, R. Fitzgerald, G. W. Hull, Jr, H. L. Luo, B. T. Matthias and W. H. Zachariasen, Proc. Natl. Acad. Sciences, 1968, 61, 621

24 G. W. Webb, L. J. Vieland, R. E. Miller and A. Wicklund, Solid State Commun., 1971, 9, 1769

25 E. Röschel, O. Loebich, Jr. and Ch. J. Raub, Z. Metallkunde, 1973, 64, 359

26 H. R. Khan, E. Röschel and Ch. J. Raub, Z. Phys., 1973, 262, 279

27 E. C. van Reuth, R. M. Waterstrat, R. D. Blaugher, R. A. Hein and J. E. Cox, Proc. 10th Internat. Conference Low Temp. Physics Vol. IIB, p. 137; R. A. Hein, J. E. Cox, R. D. Blaugher, R. M. Waterstrat and E. C. van Reuth, Proc. Internat. Conference Science of Superconductivity, Stanford University, Stanford, California, $1969 ; \mathrm{E}$. C. van Reuth and R. M. Waterstrat, Acta Cryst., 1968, 24, 187; R. A. Hein, J. E. Cox, R. D. Blaugher, R. M. Waterstrat and E. C. van Reuth, Physica, 1971, 55, 523

28 B. W. Roberts, Progress in Cryogenics, Vol. 4, Heywood, London, 1964, p. 160

29 T. F. Smith and H. L. Luo, F. Phys. Chem. Solids 1967, 28, 569

30 M. C. Krupka, A. L. Giorgi, N. H. Krikorian and E. G. Szklarz, f. Less-Common Metals, 1969, 19, 113

\section{Gold-Chromium Films for Solar Energy Conversion}

The optical properties of thin films of gold and of certain of its alloys make them particularly suitable for use in solar energy collectors and concentrators. In particular, films of gold-chromium alloys offer not only high resistance to corrosion in this field but improved mechanical properties and excellent adhesion to glass.

More detailed data on the properties of gold and a series of gold-chromium alloys have now been reported by a team of investigators at Rutgers University, B. Lalevic, W. Slusark, A. Delahoy and the late N. Fuschillo (F. Vac. Sci. Technol., 1975, 12, (1), 84-87), The work, supported by P.P.G. Industries, involved transmission and reflectance measurements on sputtered gold-chromium films of two types-opaque films $1500 \AA$ in thickness and thin films ranging from 100 to $400 \AA$. The results are used to calculate figures of merit for the heat mirror type of solar energy collector. 